\title{
Enhancement of the building simulation software TRNSYS by coupling to the VEPZO model programmed in Modelica
}

\author{
Svea Kübler ${ }^{1,2}$ \\ Victor Norrefeldt ${ }^{1}$ \\ 1: Fraunhofer-Institute for Building Physics, Fraunhoferstr. 10, D-83626 Valley \\ 2: Transsolar Energietechnik GmbH, Curiestr. 2, D-70563 Stuttgart \\ $\underline{\text { svea.kuebler@ibp.fraunhofer.de victor.norrefeldt@ibp.fraunhofer.de }}$
}

\begin{abstract}
In this study, the possibility to interface a commercial building simulation tool with Modelica models is investigated. In this application, the zonal model VEPZO - modeled in Modelica - is coupled to the software TRNSYS - mainly programmed in Fortran - to be able to perform a dynamic co-simulation. The objective of this coupling is to obtain refined airflow and air temperature prediction, while retaining computation effort low enough to allow for transient computation. In a first attempt, a coupling using FMI was tested without success due to a lack of adequate solvers for FMI export. Therefore, a script coupling was implemented. Further steps include a validation and evaluation of the programmed interface and the results of the coupled system in respect to computation time, quality of results, usability and further development.
\end{abstract}

Keywords: building simulation; zonal model; FMU, Dymola scripting, TRNSYS

\section{Introduction}

Building simulation tools are used to assess building energy consumption, building control strategies, system performances, etc. on an annual or longer basis. In Modelica, the Buildings Library [1] and the Indoor Climate Library [2] contain models for the simulation of building energy performance. These libraries allow the simulation of building models directly in Modelica. Beside these, various commercial and free non-Modelica building simulation software products are available on the market. User's experience, knowledge of a specific tool and availability of tools in companies and institutes determine which software is used. Therefore coupling of different tools becomes interesting when a specific model reaches its limits. In the presented study, an interface has been established for TRNSYS and the VEPZO model [3; 4] (programmed in Modelica) in order to enhance the simulation of atria.

\subsection{TRNSYS}

TRNSYS (Transient Systems Simulation) development started at the University of Wisconsin in 1975. The latest version 17 was released in 2010. TRNSYS code has a modular approach and is structured into types. Each type contains code for a specific task, usually representing a model of a specific component such as a part of an HVAC system. Types have a common structure and communicate via a given set of inputs, outputs and parameters. A central type for building performance simulations is the multizone building simulation environment (Type 56). It subdivides a building into multiple zones with homogeneous properties and conditions. The computation includes heat flows due to radiation, convection, conduction and solar gains and enthalpy flows through ventilation and air leakages. The integrated code COMIS [5] allows the formation of an airflow network by interconnecting zones. A schematic setup of the physical phenomena in an atrium is shown in Figure 1. 


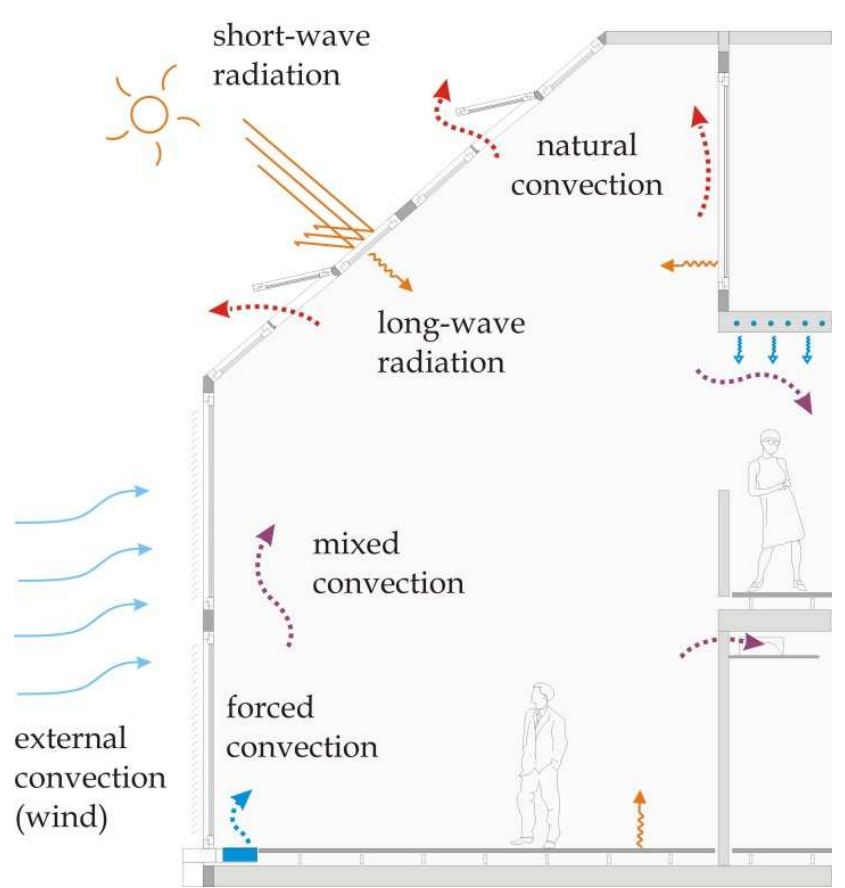

Figure 1: Schematic atrium model

The assumption of a perfectly mixed zone reaches its limits when simulating atria, because solar heat gains through glazing and a considerable height lead to thermal stratification of air. The current solution method to simulate atria in TRNSYS is to subzone them. For this, several air nodes are created in the atrium connected to one another by a predefined mass flow. To set up the model properly, the modeler requires prior knowledge of the airflow pattern either from experience or from CFD simulations. However, even experienced modelers may fail to provide the proper airflow pattern. Due to a high requirement in computational power, CFD simulations are currently applicable for only a few configurations of different boundary conditions and only under steady-state conditions. Therefore, the extension of TRNSYS by a simpler airflow model is of interest.

\subsection{VEPZO}

The velocity propagating zonal model (VEPZO) was developed to fill the gap between the computationally cheap but inaccurate assumption of perfectly mixed air volumes and the slow but accurate CFD computation. Typically, a space is subdivided into $10^{1}$ to $10^{2}$ zones exchanging air [6]. The main components are a zone and a flow model which are connected by ports (Figure 2). Zone models possess a heat port to exchange convective heat flows from walls, equipment, humans, etc. In the zone model, conservation of energy and mass are implemented.
The flow model computes the airflow between adjacent zones resulting from pressure, momentum and height differences and losses. Velocity information is propagated through the models allowing the prediction of temperature and velocity distributions without prior knowledge of the airflow pattern. Models from the Modelica.Media package are used to compute air properties. Dymola is used as compiler for VEPZO. Results of the VEPZO model are the airflow pattern and temperature distribution in the considered space. Hence, it is suited to give a quick estimation of flow and air temperature conditions in an atrium.

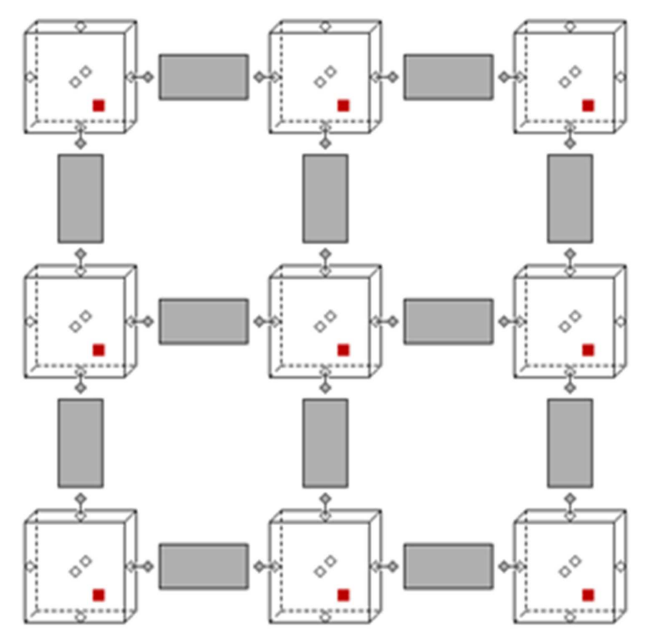

Figure 2: VEPZO model in $\mathrm{x}-\mathrm{z}$ direction ( $\mathrm{y}$ not shown); cubes: zones; grey rectangles: flows; rhombs: airflow ports; red solid squares: heat ports.

\subsection{Model coupling}

TRNSYS and VEPZO are coupled to benefit from the respective strengths of the codes. The goal is to obtain a correct simulation of the energetic performance and climatic conditions in an atrium without prior knowledge of the airflow pattern.

TRNSYS has already been used for co-simulation with other tools such as ESP-r, Energy-Plus and Matlab [7; 8]. All couplings use TRNSYS as a master and exchange data through a TRNSYS type which translates data into the required format.

For the coupling of Modelica models to other simulation environments several possibilities exist. A powerful tool is the Building Control Virtual Test Bed (BCVTB), an interface for building simulations developed by the Lawrence Berkeley National Laboratory. It already provides an interface for Modelica and TRNSYS. However, the coupling currently does not allow for iterations between components 
[9]. Therefore, it is not suitable for a dynamic cosimulation as envisaged in this application.

In recent years the FMI-standard has been established for model exchange with other software environments [10]. It has already found several applications in building simulation technology [11] and is especially suited for Modelica models. Another possibility to couple other software to Modelica (Dymola) is the use of script files in the .mos-format which are automatically created and whose execution is launched in the command processor.

\section{Method}

TRNSYS and VEPZO communicate at the inner wall surface of the investigated atrium where TRNSYS passes the wall surface temperature to VEPZO. With this information, VEPZO computes the heat flow rate from the wall to the adjacent zone and hence resulting airflow and air temperature distributions. The heat flow rate is returned to TRNSYS to compute the energy balance (Figure 3). This coupling is iterated until the total energy balance converges below a defined threshold.

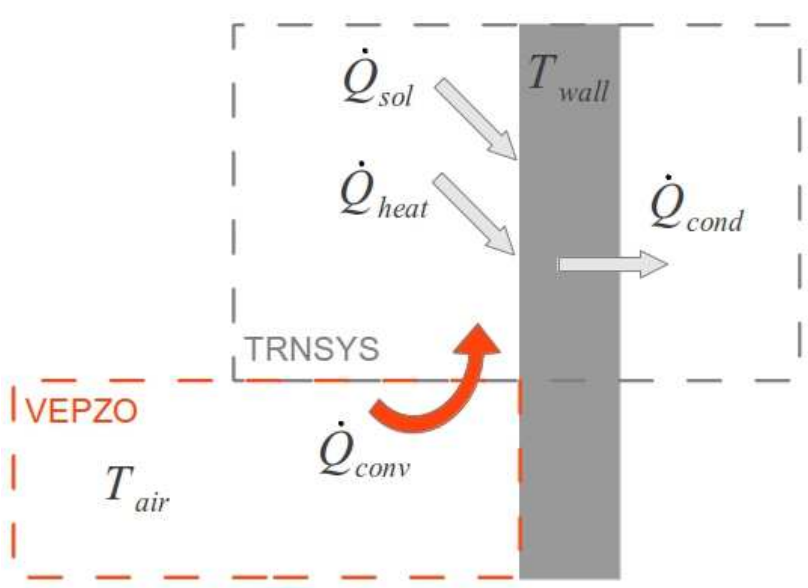

Figure 3: Heat flows and temperatures computed by the two interfaced tools

Both TRNSYS and the Modelica model VEPZO required some preparation before being interfaced. TRNSYS air nodes, which are required in the simulation environment, are inactivated by setting convective heat transfer coefficients to zero. The convective heat flux is then replaced by the one obtained from VEPZO.

VEPZO required TRNSYS convective heat transfer correlations to be implemented in the model. Input and output connectors were included to receive the surface air temperature and to deliver the heat flow.
Furthermore, supply airflow rate and temperature as well as exhaust opening pressure were set as inputs.

\subsection{Model coupling via FMI}

First attempts to simulate VEPZO as an FMU showed that in spite of having set input values for air temperatures and pressures, the FMU instantiates with all inputs being zero. This generates an error in the air model from Modelica.Media as $0 \mathrm{~K}$ and $0 \mathrm{~Pa}$ are out of definition bounds. Therefore, temperature and pressure offsets were introduced in the model (273.15 K, $101325 \mathrm{~Pa}$, Figure 4). Thus, the temperature input is in ${ }^{\circ} \mathrm{C}$ and the pressure input gives the deviation from standard pressure.

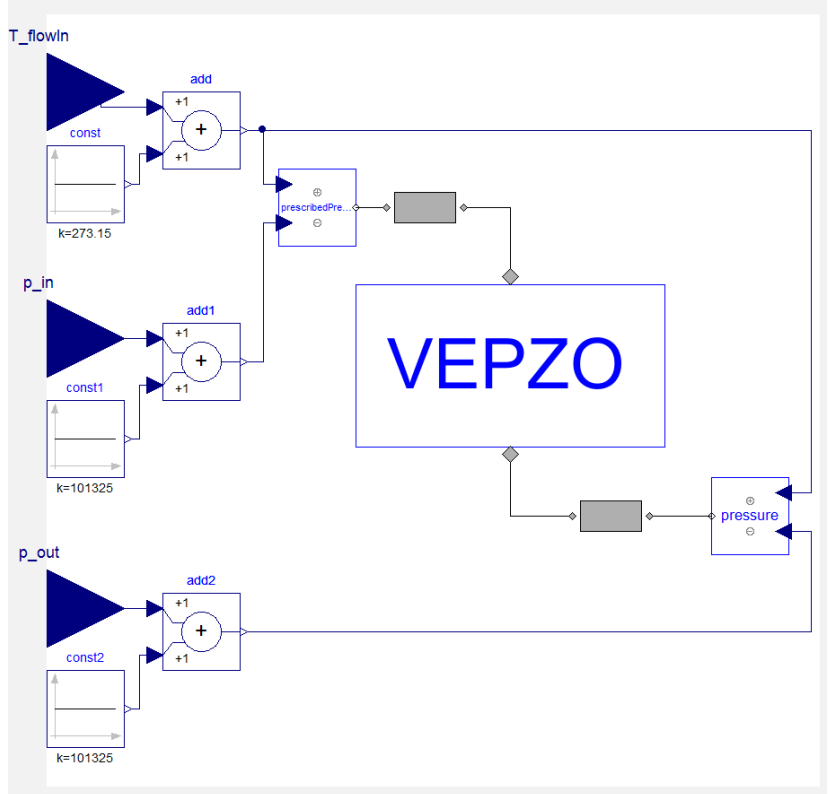

Figure 4: Introduction of temperature and pressure offset prior to FMU export

To allow the import of a VEPZO-FMU to TRNSYS, the new TRNSYS type was implemented (Figure 5). At the very first call the new type checks that the given FMU is suitable for co-simulation, retrieves the reference values of input and output parameters of the model and opens a result file which can be continuously accessed during the simulation. Then, the following steps are iterated:

1. Receive input values and current time as well as time step size from TRNSYS

2. Load the VEPZO-FMU

3. Instantiate VEPZO-FMU

4. Load values from the previous time step from internal storage

5. Initialize VEPZO-FMU with values from the previous time step 
6. Perform calculation from the current to the next time step

7. Write results

8. Pass output values to TRNSYS.

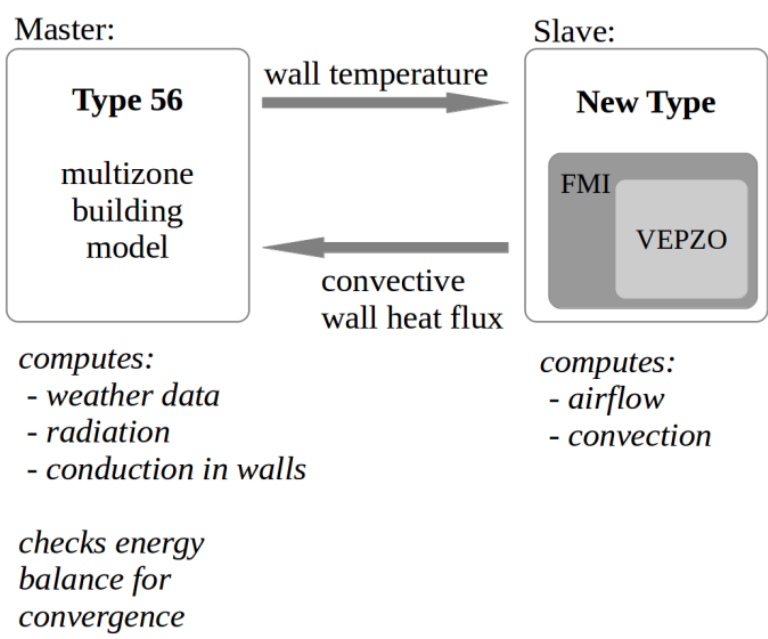

Figure 5: Basic structure of the two coupled tools in the interface via FMI

The coupling was implemented and simulation time showed to be significantly prolonged in comparison to VEPZO simulations in Dymola. When simulating a simple test case with a supply mass flow rate of $0.1 \mathrm{~kg} / \mathrm{s}$, supply temperature of $10^{\circ} \mathrm{C}$ and wall temperature of $30^{\circ} \mathrm{C}$ the air temperature predicted by the FMU showed an unstable range between $180 \mathrm{~s}$ and $500 \mathrm{~s}$ simulation time in comparison to the simulation in Dymola (Figure 6). The reason for this is that VEPZO requires a fifth-order stiff Runge-Kutta solver in order to be solved for low supply mass flow rates. This solver is not available for export in the current version of Dymola, but will be implemented in future versions [12]. Hence the dynamic coupling of TRNSYS and VEPZO via FMU was discarded in this study.

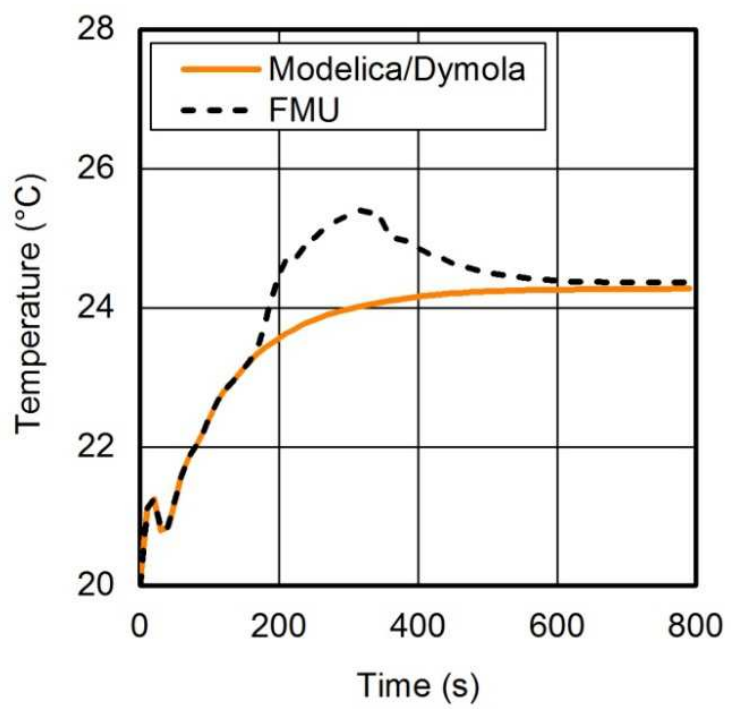

Figure 6: Comparison of Dymola and FMU simulation of a simple test case in VEPZO

\subsection{Model coupling through scripting}

In a second approach TRNSYS and VEPZO were coupled using Dymola scripting. For this, another new TRNSYS Type was implemented. This type writes and executes a .mos-file containing wall temperatures, simulation settings and code for export of computed wall heat flow rates into a .csv file. The new type reads the .csv file and uses it as input for the thermal building simulation (Figure 7).

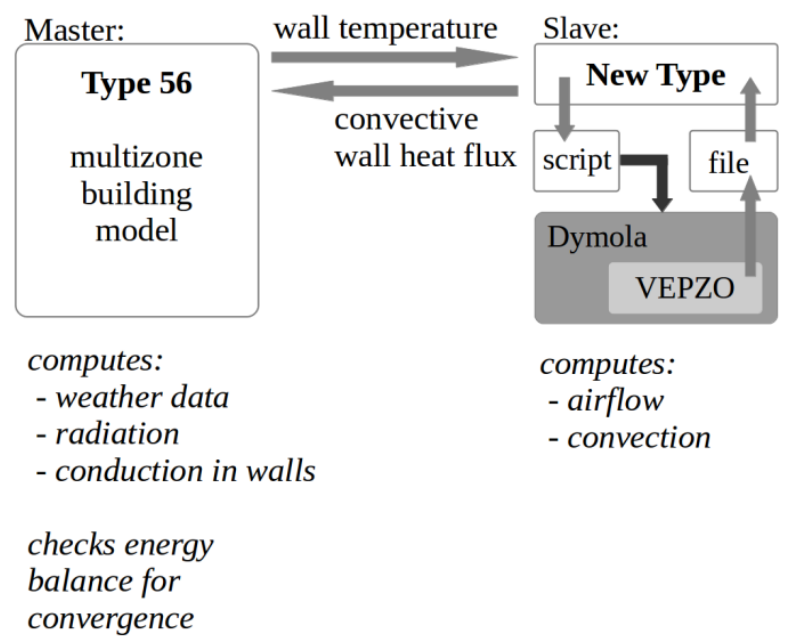

Figure 7: Basic structure of the two coupled tools in the interface via scripting 


\section{Atrium model}

To demonstrate the coupled simulation of TRNSYS and VEPZO an atrium is modeled and simulation results are compared to data from measurements and CFD simulations. The modeled atrium (Figure 8) is part of the Concordia University engineering building located in downtown Montreal $\left(45.5^{\circ} \mathrm{N}, 74^{\circ} \mathrm{W}\right)$. In total, five atria each covering three floors are placed on top of each other. The considered atrium is of rectangular geometry and can be conditioned by both natural and mechanical ventilation. Mouriki [13] conducted measurements in this atrium at four days ranging from August to November 2007. Based on this data, Hussain [14] carried out several CFD simulations of this atrium with different turbulence models.

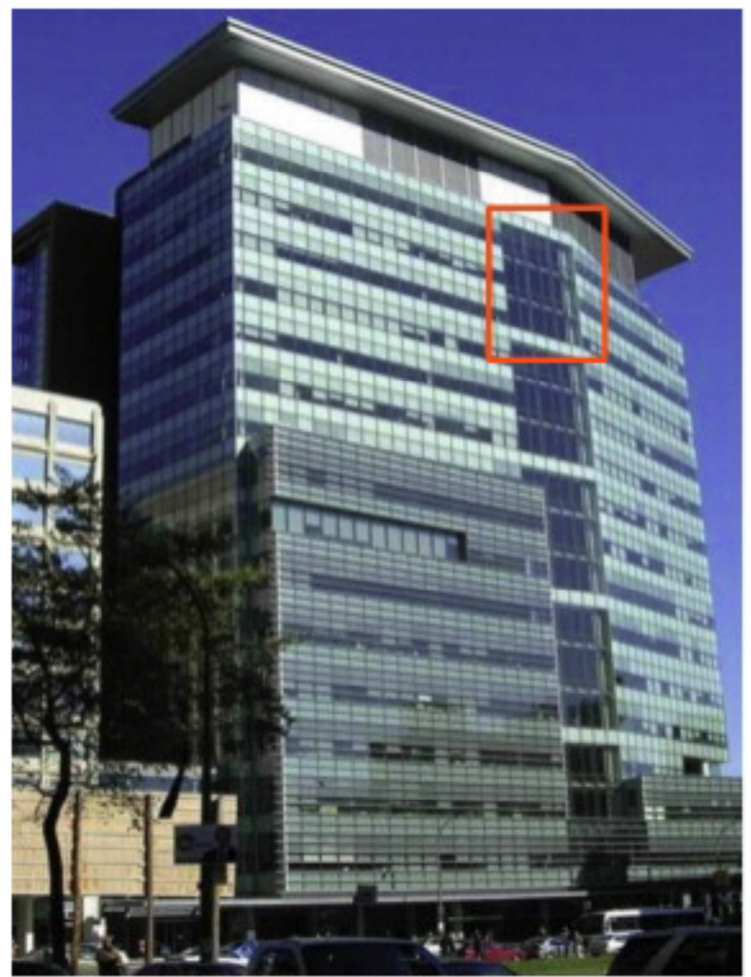

Figure 8: Considered atrium

To reduce the uncertainty of boundary conditions, a day with only mechanical ventilation (November $2^{\text {nd }}$ 2007) has been selected for comparison. It was a clear and cold day with ambient temperatures between -1.5 and $8{ }^{\circ} \mathrm{C}$. The maximum global horizontal radiation for a nearby weather station was $480 \mathrm{~W} / \mathrm{m}^{2}$ [15]. Measurement readings are available from 6am to midnight. Figure 9 shows the geometry of the considered atrium and the location of mechanical ventilation inlet and outlet. The atrium air volume is divided into $5 \times 5 \times 6$ (length, depth, height)
VEPZO zones. To compare the coupled simulation to the classical TRNSYS approach using modeler's experience, a second simulation model using only TRNSYS was set up. In this model, air is subdivided into three horizontal slices. Walls are discretized into a total of 20 facets in order to account for different wall temperatures due to varying solar radiation. For this work, we could not access construction plans of the atrium. The only hint to guess materials are published pictures and transient temperature measurements. Therefore, this information presents a considerable source of error which is mainly reflected in the thermal capacity of the system.

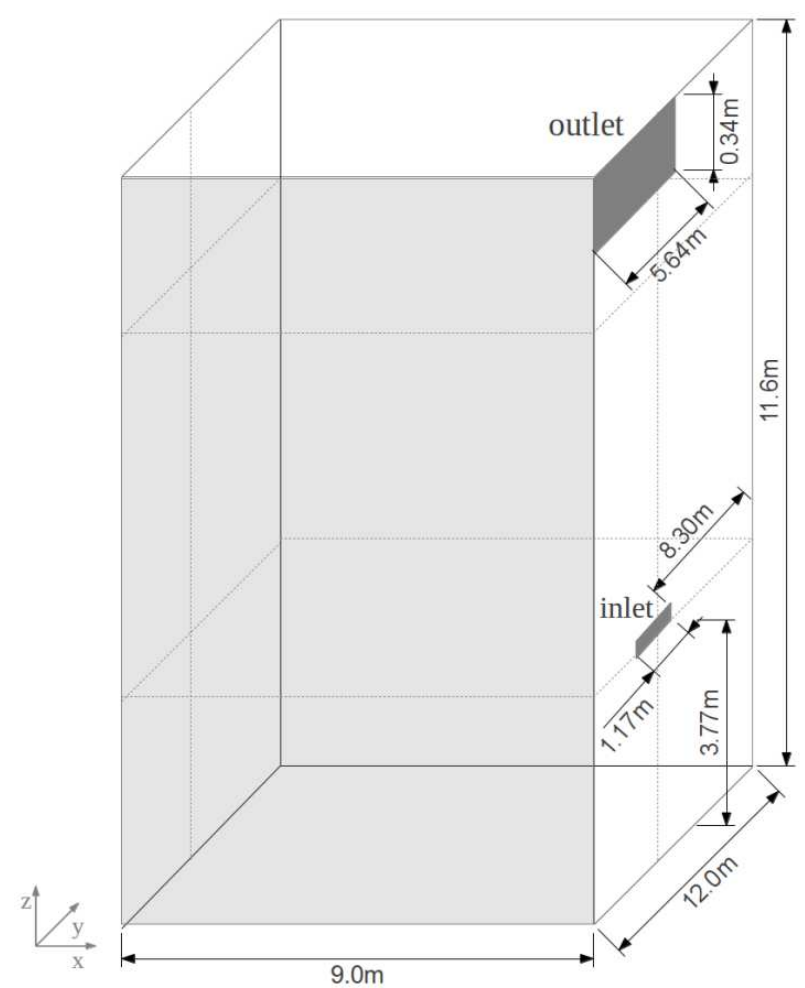

Figure 9: Geometry of considered atrium

The boundary conditions obtained from measurements are inner glazing surface temperatures, transmitted solar radiation, ambient temperature and supply air conditions (Figure 10). To acquire a proper initialization of wall temperatures, four days prior to the considered day were simulated before the coupled simulation was started. The coupled simulation took $4 \mathrm{hr}$ and $45 \mathrm{~min}$. 

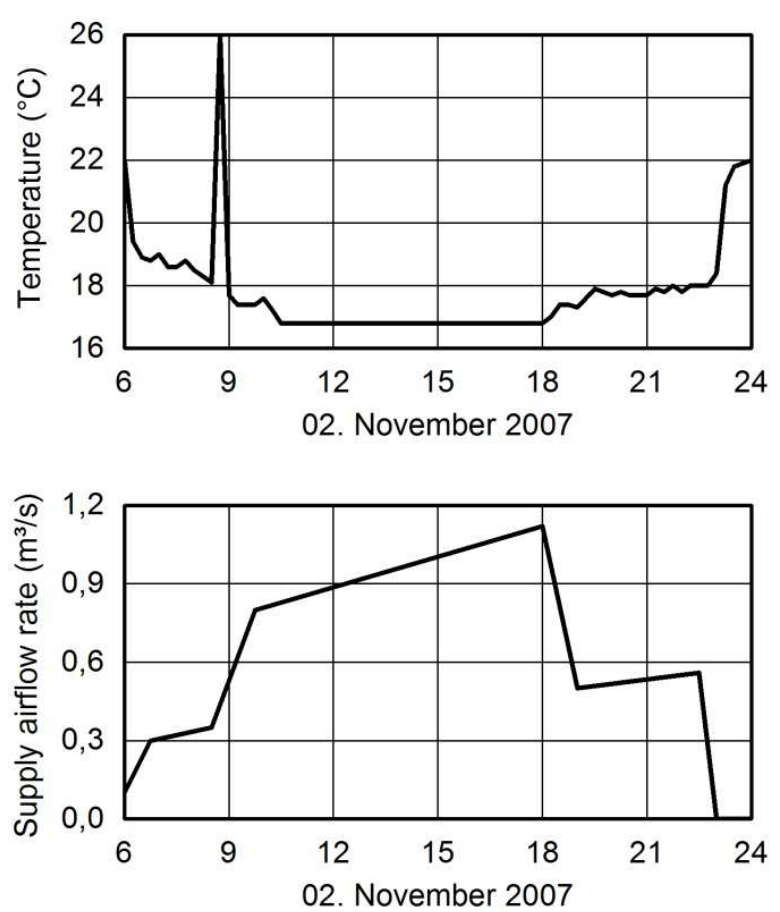

Figure 10: Supply air boundary conditions

Figure 11 shows the comparison of measurement and coupled simulation for the average temperature in three heights of the atrium. Five main observations are made:

- The results from the coupled simulation show an initial drop in air temperature which causes the further temperature profiles to be lower than measured.

- The peak in temperature is reached by about one hour delay in the simulation but shows good coherence in the absolute value with the measured peaks.

- The model is more sensitive to a change in airflow boundary condition than measurements show.

- A raise in temperature due to a lower cooling flow rate around $6.30 \mathrm{pm}$ can only be observed at the lowest measurement position but is observed for all heights in the simulation. The same is the case for the shut-down of the ventilation around $11 \mathrm{pm}$.

- As a result, the air temperature at the end of the simulation is about $2 \mathrm{~K}$ higher than measurement shows.

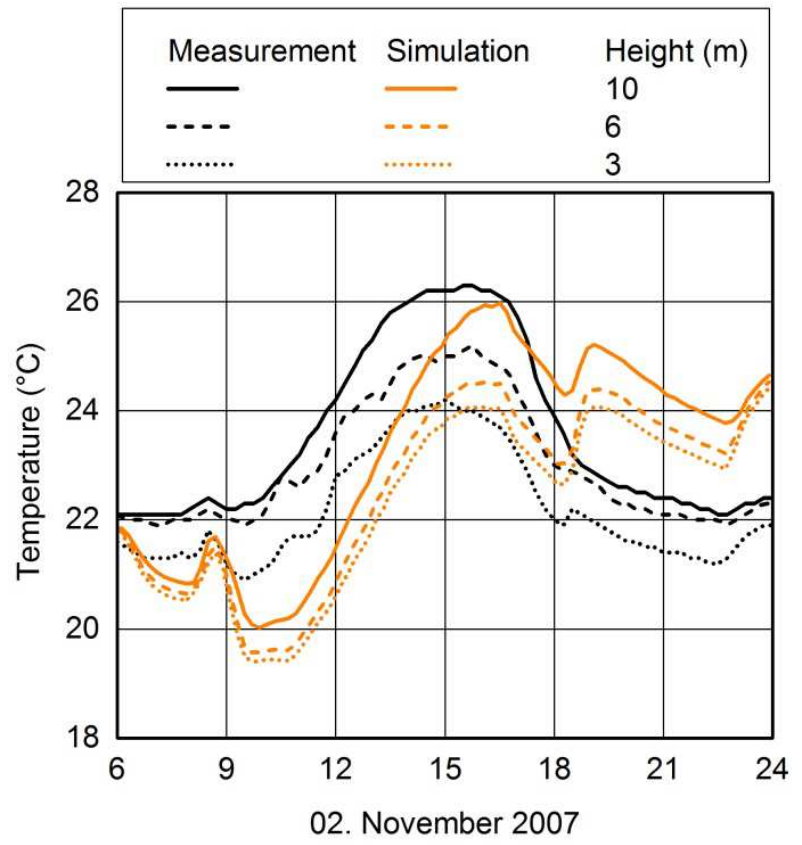

Figure 11: Temperature at three different heights over the course of one day

Figure 12 shows a comparison of measured air temperature profile, coupled simulation results and CFD simulations [14] for $4 \mathrm{pm}$. The coupled simulation shows considerably better agreement to measurements than CFD simulations do.

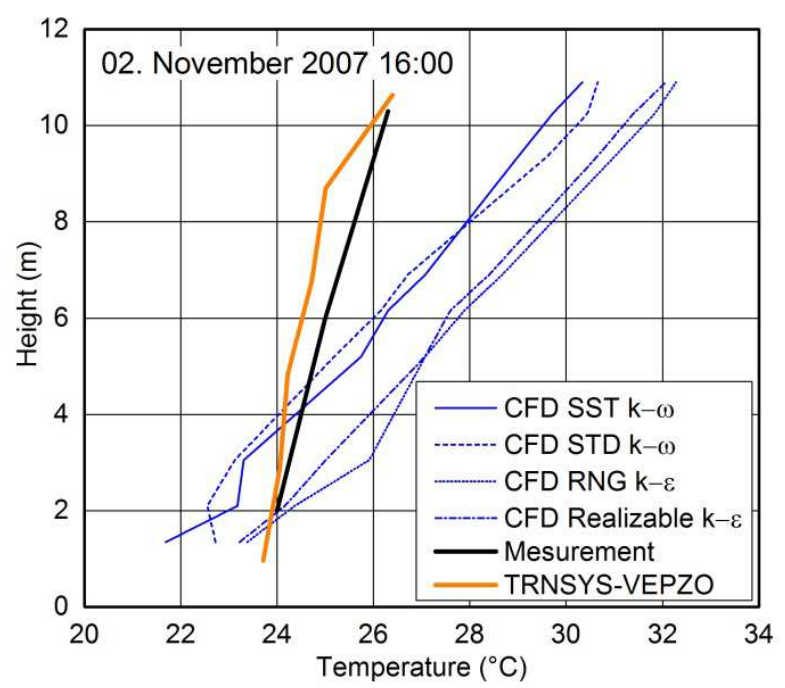

Figure 12: Comparison of simulated and measured temperatures over the height at $4 \mathrm{pm}$ 


\section{Discussion}

The higher rate of response of air temperature of the model to variations in air supply suggests that it does not contain enough thermal capacities dampening variations of boundary conditions or that the convective heat coefficient model is inaccurate. Additional capacities can for example be caused by furniture and other internal objects like stairs. The initial drop in temperature implies that the surface's temperatures are lower in the simulation than they are in reality. This could be caused by a lower thermal mass of walls in the model or because the atrium gains energy from surrounding rooms during the night.

Between 3 and $4 \mathrm{pm}$ relatively stable temperature conditions are present in the atrium. For this case, the coupled simulation gives better results than CFD computations. The reason is that it is very difficult to obtain a good prediction of airflow by CFD for such large volumes with comparatively small openings without an adequate benchmark case.

The results from the dynamically coupled simulation in comparison to those obtained from a TRNSYS simulation show that very similar temperature profiles can be achieved for simple configurations where the airflow pattern can be predicted by experience. This implies that VEPZO results show a high dependence on the inputs obtained from TRNSYS.

\section{Conclusions and future work}

A dynamic coupling of the building simulation tool TRNSYS and the Modelica model VEPZO has been implemented successfully using Dymola scripting. A coupling through FMI was not successful due to missing solvers for FMI for co-simulation export.

The results obtained from the dynamically coupled simulation show significant dependence on the TRNSYS model, especially on the proper knowledge and implementation of the building construction (materials, capacities, etc.). If those are modeled accurately, coupled simulations can give good predictions of airflow and air temperature as required in the building planning process. In comparison to CFD, results of the coupled simulation show better coherence with measured data.

The usability of the current coupling method should be improved by speeding up computation times and facilitating geometry specific scripting. It could be increased by using FMI once the required solvers are available for export. It would be helpful if FMI instantiation could be performed at values different from zero to avoid error-prone preparation of the Modelica model.

Further development of VEPZO as deduced from this study includes the implementation of heat transfer correlations which take into account the wall orientation and flow velocity. Additionally the feature of an artificial internal heat capacity will be integrated in order to be able to model furniture.

Regarding the interface, a possible further development is the integration of the multi-zonal model COMIS into the interface such that boundary conditions at atrium openings can be obtained from a coupled COMIS-TRNSYS simulation. Once the computation time of the coupling is reduced, the interface could moreover be utilized to optimize the design of atriums and large halls such as the best location and size of ventilation openings.

\section{References}

[1] Wetter, M.: Modelica library for building heating, ventilation and air-conditioning systems, 7th International Modelica Conference, Como, Italy, 20.-22. september 2009

[2] Norrefeldt, V., Andersson, D., Pathak, A. et al.: The Indoor Climate Library and its application to heat and moisture transfer in a vehicle cabin, 9th Modelica Conference, 3.-5. september 2012, Munich, Germany

[3] Norrefeldt, V., Grün, G., Sedlbauer, K.: VEPZO - Velocity propagating zonal model for the estimation of the airflow pattern and temperature distribution in a confined space, Building and Environment, Volume 48, pp. 183-194, 2012

[4] Norrefeldt, V., Grün, G.: VEPZO - Velocity Propagating Zonal Model for the prediction of airflow pattern and temperature distribution in enclosed spaces, 9th Modelica Conference, 3.5. september 2012, Munich, Germany

[5] LBNL, consulted 7-3-2012, http://epb.lbl.gov/comis/

[6] Boukhris, Y., Gharbi, L., Ghrab-Morcos, N.: Modeling coupled heat transfer and air flow in a partitioned building with a zonal model: application to the winter thermal comfort, Building Simulation, Volume 2, pp. 67-74, 2009

[7] Beausoleil-Morrison, I., Macdonalda, F., Kummert, M. et al.: The design of an ESP-r and TRNSYS cosimulator, Building 
Simulation, 14.-16.november 2011, Sydney,

Austrailia

[8] Trcka, M., Wetter, M., Hensen, J.: Comparison of co-simulation approaches for building simulation and $\mathrm{HVAC} / \mathrm{R}$ system simulation, Building Simulation, 3.-5. septemper 2007, Bejing, China

[9] Wetter, M.: Building Controls Virtual Test Bed UserManual, 2012

[10] Modelica Association: Functional Mock-up Interface, 2012

[11] Pazold, M., Burhenne, S., Radon, J. et al.: Integration of Modelica models into an existing simulation software using FMI for CoSimulation, 9th Modelica Conference, 3.-5. september 2012, Munich, Germany

[12] Wernersson, K.: Personal Communication, 2013

[13] Mouriki, E.: Solar-Assisted Hybrid Ventilation in an Institutional Building, Master Thesis at Concordia Universtiy Montréal, Canada, 2009

[14] Hussain, S.: Numerical investigations of the indoor thermal environment in atria and of the buoyancy-driven ventilation in a simple atriumbuilding, $\mathrm{PhD}$ Thesis at the Queen's University, Montréal, Canada, 2012

[15] National Renewable Energy Laboratory: NSRDB - National Solar Radiation Data Base, United States, 2007 